\title{
Incorporating Policy Criteria in Spatial Analysis
}

Anand Desai

Robert T. Greenbaum

The Ohio State University, Columbus

Yushim Kim

Arizona State University, Phoenix

\begin{abstract}
Although spatial analysis and Geographic Information Systems (GIS) have become prevalent in the social and policy sciences, GIS and its mapmaking capability remains an underutilized tool among the decision support tools available to policy makers. Using a case study of Medicaid expenditure changes in Ohio, the authors demonstrate how spatial analysis and display can incorporate useful weights for policy makers. Through the use of dependence indices based upon the distributions of the affected recipients and service providers to weight the expenditures, the link between the effects of policy changes and the spatial distributions of these populations becomes clearer. The article argues that policy makers can be given a more appropriate picture of the potential local implications of statewide policy changes through the use of weights. Because of the power of maps to so starkly display these distributions, the article concludes with a caution that such tools should be used ethically with considered judgment.
\end{abstract}

Keywords: Geographic Information Systems; spatial analysis; visual display; Medicaid policy; location quotients

$\mathrm{M}$ aps that range in sophistication from simple pictures drawn on the back of an envelope to depict the relative locations of a few landmarks to detailed illustrations obtained through the use of benchmarks and sophisticated surveying tools provide visual representations of data in a spatial context. Maps, as data visualizations, serve a vital purpose in helping us make sense of spatial distributions. For instance, Topologically Integrated Geographic Encoding and Referencing system (TIGER) maps produced by the U.S. Census Bureau illustrate the distribution of demographic characteristics of the United States. ${ }^{1}$ Variations in environmental conditions across the United States can be seen in the maps provided in the Environmental Protection Agency's Envirofacts Data Warehouse, ${ }^{2}$ whereas maps accompanying the Regional Economic Accounts produced by the Bureau of Economic Analysis (2001) of the U.S. Department of Commerce show the spatial distribution of economic activity across the United States. ${ }^{3}$ Although it is clear that maps are effective data

\footnotetext{
Authors' Note: We would like to thank Tim Champney, William Hayes, and Lorin Ranbom for their help, and we appreciate the feedback from the four anonymous referees. We are also grateful to the Health Policy Institute of Ohio and The Health Foundation of Greater Cincinnati for their financial support. The authors are listed in alphabetical order and indicate equal contribution. We remain responsible for all errors.
}

Initial Submission: October 10, 2006

Accepted: October 13, 2007 
visualization tools, this article explores how they, and in particular, Geographical Information Systems (GIS), aid public policy analysis and decision making. GIS and spatial analysis tools add another important dimension by introducing spatial considerations into the analysis of the distributional effects of public policy changes.

To assist public decision makers, GIS must provide compelling pictures of data that highlight the distinctions among the available choices. We contend that GIS is an underutilized tool and that its proper use can enhance diagnostic capability. Maps are powerful data visualization devices, and the ability of GIS to manipulate these data displays provides decision makers information in a form that is simultaneously dense and yet easy to interpret. Our purpose here is to illustrate that maps can be coupled with nonspatial and spatial analytical tools to create visual displays that allow analyses that are more subtle than those available through the use of data analysis or data visualization tools alone. Implementing different weights on decision variables implied by different policy options allows measurement of the consequences of different policies. The representation of this information on maps offers decision support not readily available through tabular displays of data.

Thus, the article does not set out to suggest that there is a unique, superior weighting scheme or data representation. Instead, we will demonstrate that sets of policy choices can lead to a variety of spatial consequences, and that GIS, when coupled with differential weights on the decision variables, can make the distinctions among the consequences of the different policy options easier to see. This visualization ultimately makes the analysis more useful for the decision makers.

\section{Bringing Spatial Analysis into the Policy-Making Process}

GISs integrate computer-based database capabilities for managing spatially referenced data with the tools for modeling and testing research hypotheses and analyzing management and planning challenges. A GIS also includes a decision support system to help both structure problems and develop solutions (Worrall \& Bond, 1997). This notion goes beyond the usual description of GIS as a sophisticated database. Going beyond data management and representation, a GIS is seen as a part of an organization's information system that supports the decision-making processes of the organization.

By marrying the power of maps to present large amounts of complex information with the database management and computational capabilities of increasingly fast computers, GIS has become, in recent decades, one of the external aids that enhance our cognitive abilities. In the public sector, particularly at the local level, GIS is used for a vast array of activities, including everything from transportation, infrastructure, and community development planning to environmental protection, public safety response, and election management to property assessments, facility siting, and real estate management (Haque, 2001). The use of GIS as a tool for facilitating and enhancing these functions by improving their efficiency and accuracy has been discussed at length elsewhere (e.g., Brown \& Brudney, 1998; Foresman, 1998; Haque, 2001; Hissong \& Couret, 1999; Martin, 1996; Masser, 1998; NAPA, 1998; O'Looney, 2000; Ventura, 1995). Many of these GIS applications consist of visual representations of the topics at hand on a map. For instance, they depict how changes in zoning laws would change the distribution of different types of land use, or they show concentrations of pollutants 
and other hazards. The GIS analyses usually focus on proximity in terms of some measure of distance. What is feasible, but not often implemented, is the ability to use weights to reflect stakeholder values and preferences.

Public policy emanates from a set of values that yield intentions, rules, processes, implementation, and enforcement to produce policy outcomes (Wildavsky, 1987). We have suggested that GIS is not only a tool for enhancing routine managerial and administrative functions, but it is also a powerful communication device (Greenbaum \& Desai, 2005). We further suggest here that GIS, supplemented by spatial statistics and weighting procedures, can assist in developing policy arguments and in informing policy choices. We illustrate the use of GIS as a decision support tool in the context of budgetary changes regarding Medicaid expenditures in Ohio.

In the next two sections, we lay out the context for the changes in Ohio's Medicaid expenditures. We then suggest alternative spatial mechanisms to weight expenditures at the county level and illustrate with maps the implications of the various weights. We conclude with a brief discussion noting that analysts must proceed with caution when using these tools to assist policy makers' decision making.

\section{A Case Study: Budgetary Pressures on Medicaid}

The Medicaid program, which provides medical coverage for the poor and needy in the United States, is funded through collaboration between the states and the federal government. State funding is matched by the federal government at varying levels, depending on the type of program. This federal support can vary from an even match to sometimes as much as $\$ 2$ for every dollar spent by the state. During the economic boom of the second half of the 1990s, states' revenues grew rapidly enough to allow taxes to be reduced while expenditures continued to expand. This blissful period ended in mid-2001 when states' fiscal situations quickly began to reverse. During this time, Medicaid enrollments grew rapidly and expenditures, particularly on prescription drugs, also rose sharply (McGarry, 2002; National Governors Association, 2003; Smith, Ellis, Gifford, Ramesh, \& Wachino, 2002). Although expenditures vary from state to state based on the eligible populations and services provided, Medicaid now averages $21 \%$ of overall state expenditures, which is twice what it was 15 years earlier (Marton \& Wildasin, 2007). To address this, legislators at both the state and the federal levels have been seeking to reduce the rate of growth in Medicaid expenditures. Some of the more common changes include reduced payments to service providers, reduced or eliminated benefits, stricter eligibility criteria, and increased costs to service recipients.

Overall analyses of state budgets provide legislators with reliable estimates of what the Medicaid expenditures must be in order to balance the state budget. The debates have focused not only on overall expenditures but also on which of the many programs funded by Medicaid must withstand the deepest of the cutbacks in the growth of the expenditures. The role of policy analysis in this context is to provide decision support to politicians making the decisions. Hence, the task is to inform the political debate by providing analyses of the differential effects of these expenditure proposals on constituent groups such as taxpayers, medical service providers, local public service organizations, and Medicaid recipients. For instance, changing eligibility criteria for dental services will affect a different group of recipients than 
those affected by reducing the rate at which prescription drug expenditures are allowed to rise. Depending upon where reductions in growth are implemented, the effects on different social, economic, and demographic groups will vary. Depicting these consequences on maps helps to facilitate the inclusion of spatial distributional considerations into the analysis, and consequently, decision making. For instance, analyses in North Carolina (Kilpatrick, Olinick, Luger, \& Koo, 2002), Ohio (Desai, Kim, \& Greenbaum, 2005), South Carolina (Division of Research, 2002), and in the urban areas of Montana (Seninger, 2003) show the varying consequences of different levels of expenditure reductions on the number of jobs and income in the local communities.

By displaying the information on maps, GIS provides powerful visual representations of the spatial distributions of these consequences. In fact, we argue that it is possible to introduce values and preferences into the analysis to explore the use of different preference structures that highlight different consequences and could therefore lead to different policy choices. Legislators and other decision makers consider a number of trade-offs in their resource allocation decisions. An important aspect of the political decision making is the spatial distribution of the consequences of different policy choices. By developing multiple weighting indices to reflect different decision criteria, we show that the spatial consequences implicit in these trade-offs can be explored to help inform the policy decisions. We use data from Medicaid in Ohio to illustrate how weighting schemes can be operationalized for such spatial analyses.

\section{Ohio Medicaid}

The Ohio Department of Job and Family Services (ODJFS) administers Ohio's Medicaid program. They rely on six state agencies, departments of job and family services, and boards of mental retardation and development disabilities in each of the 88 counties, 56 behavioral health boards, eight managed care organizations, and 46,800 health care providers. The program currently accounts for $3 \%$ of the state's economy, and the $\$ 13.3$ billion spent in 2006 now constitutes the state's top budget item and represents almost $27 \%$ of total state government spending (Health Policy Institute of Ohio, 2007). As in other states, Ohio has attempted to control this growth in spending by reducing services, tightening eligibility criteria, and reducing reimbursements to health care providers.

\section{Data}

As can be seen in Table 1, county-level data for the analysis come from four sources. Measures of the number of Medicaid recipients and Medicaid expenditures by both eligibility and service type categories in state fiscal year (SFY) $2003^{4}$ come from the ODJFS. Estimated total population, total number of households, and the number of households in poverty come from the U.S. Census Bureau (2001). Transfer payments in 2002, which include means-tested income maintenance transfers as well as social security and veterans benefits, come from The Ohio Department of Development's Office of Strategic Research (2002). Finally, 2002 data on the total number of establishments in each county and the number of establishments in the health care sector, as well as their employment and payroll, come from County Business Patterns (U.S. Census Bureau, 2002). 
Table 1

Data Sources

\begin{tabular}{|c|c|c|c|}
\hline Measure (County-Level) & Source & Year & Mean \\
\hline Residents & Census estimates & 2003 & 129,952 \\
\hline Medicaid recipients & ODJFS & 2003 & 23,976 \\
\hline$\%$ of Medicaid recipients & ODJFS & 2003 & 18 \\
\hline Medicaid provider expenditures & ODJFS & 2003 & $\$ 95,841,649$ \\
\hline \multicolumn{4}{|l|}{ Poverty Index (PI) } \\
\hline Transfer payments (\$ million) & ODD & 2002 & $\$ 612$ \\
\hline Households in poverty & Decennial census & 2000 & 13,303 \\
\hline Medicaid recipient expenditures & ODJFS & 2003 & $\$ 97,805,516$ \\
\hline Total households & Decennial census & 2000 & 50,530 \\
\hline \multicolumn{4}{|l|}{ Health Index (HI) } \\
\hline Health care establishments & County Business Patterns & 2002 & 299 \\
\hline Total establishments & County Business Patterns & 2002 & 3,081 \\
\hline Health care payroll ( $\$$ million) & County Business Patterns & 2002 & $\$ 245$ \\
\hline Total payroll (\$ million) & County Business Patterns & 2002 & $\$ 1,757$ \\
\hline Health care employment & County Business Patterns & 2002 & 7,712 \\
\hline Total employment & County Business Patterns & 2002 & 53,846 \\
\hline $\begin{array}{l}\text { Medicaid recipient expenditure } \\
\text { weighted by PI }\end{array}$ & Constructed & 2003 & $\$ 4,168$ \\
\hline $\begin{array}{l}\text { Medicaid recipient expenditure } \\
\text { weighted by HI }\end{array}$ & Constructed & 2003 & $\$ 39,589$ \\
\hline
\end{tabular}

Note: ODJFS = Ohio Department of Job and Family Services; ODD = Ohio Department of Development; $N=88$.

In SFY2003, 2.1 million Ohioans received at total of $\$ 8.6$ billion in Medicaid care across Ohio's 88 counties. The counties vary in their population's dependence on Medicaid and other social services. Although Medicaid served an average of $18 \%$ of the state population in SFY2003, these recipients are not evenly distributed across the state, and they make up differing percentages of the county populations. The distribution of Medicaid recipients across these counties varies from a low of approximately $6 \%$ to a high of almost $39 \%$ of the county residents.

The distribution of expenditures per recipient is also uneven across counties. The expenditure-per-recipient distribution, however, is very different than the distribution of recipients because of the costs associated with different classes of recipients. Expenditures per recipient are higher in counties with higher concentrations of aged, blind, or disabled (ABD) recipients than in those with high concentrations of young children and their parents (Greenbaum \& Desai, 2005).

\section{Visualizing Aggregation Differences}

Yet another way of measuring variation in Medicaid expenditures across the state is to look at the distribution of expenditures per resident. Figure 1 shows per capita expenditures by county in SFY2003, which average $\$ 4,079$ and range from a low of $\$ 2,515$ to a high of $\$ 7,500$. The distribution may appear somewhat random across the state, although the counties 


\section{Figure 1}

\section{Medicaid Expenditures per Recipient, State Fiscal Year 2003}

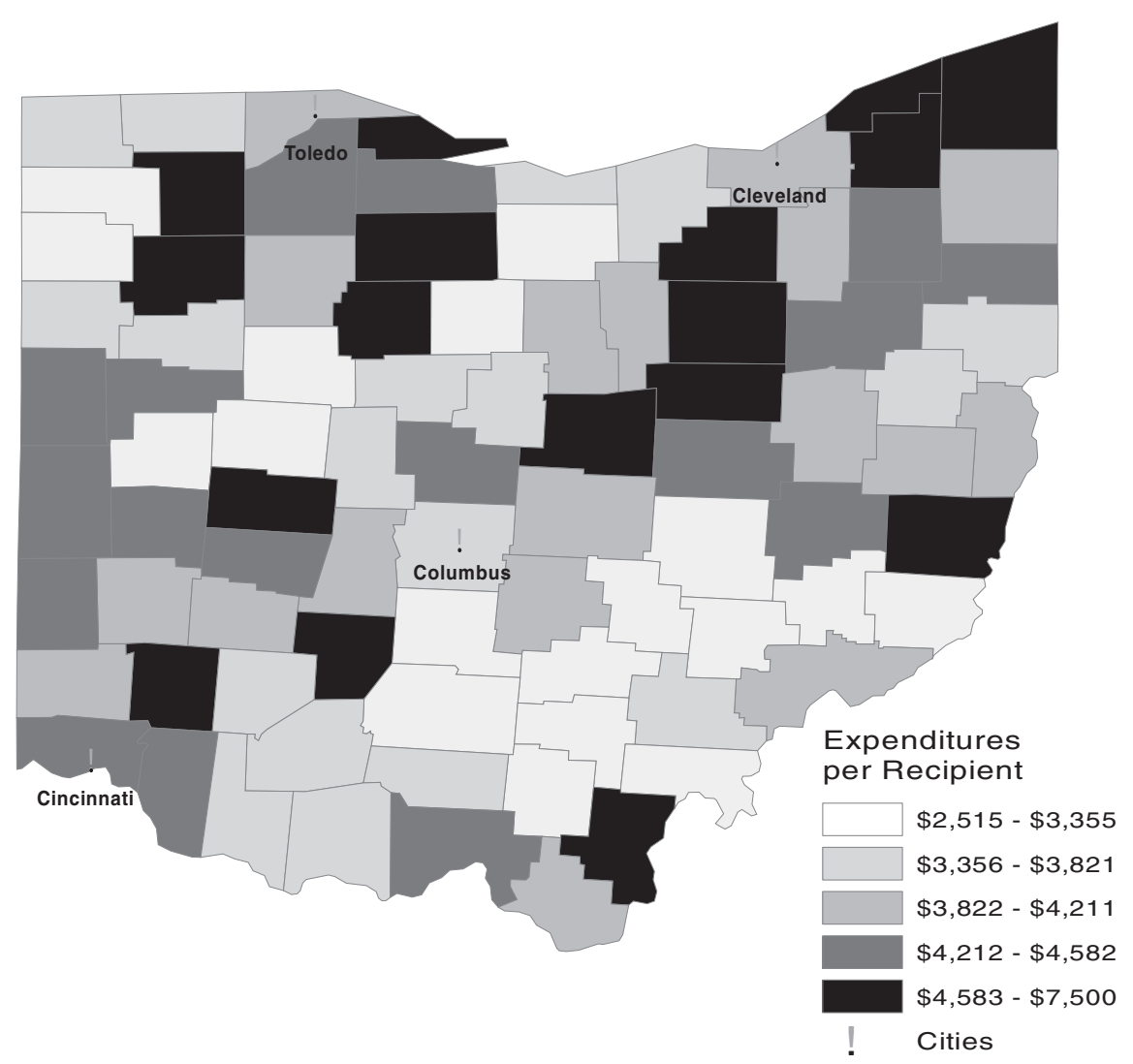

Source: Ohio Department of Job and Family Services 2003 county-level data on Medicaid recipients and expenditures.

with the highest expenditures per recipient (darkest shading ${ }^{5}$ ) are located primarily in northern counties.

To supplement the visual representation, we also provide statistical measures of variability in Table 2. A simple measure of variability is the coefficient of variation (CV), which takes into consideration the spread of the data distribution to evaluate the mean as a summary measure. ${ }^{6}$ In other words, if the spread is wide, then the mean is not as good a summary of the data values as it would be if the data are narrowly distributed around the mean. The CV for per capita Medicaid expenditures is 0.236 , indicating a relatively tight distribution. Another measure, the Gini coefficient, is the most commonly used indicator of income inequality. ${ }^{7}$ This measure to evaluate whether income is evenly distributed across the population can be extended to a spatial context to evaluate whether some other variable of interest is evenly distributed across spatially defined units. Hence, in our context we can use the Gini coefficient to measure whether Medicaid expenditures are evenly spread across 


\section{Table 2 \\ Spatial Statistics for Figure 1, per Capita \\ Medicaid Expenditures}

\begin{tabular}{lr}
\hline Spatial statistics & \\
Moran's $I$ & \\
$I$ & .103 \\
$Z$ value & 1.759 \\
$p$ value & .079 \\
Geary's $C$ & \\
$C$ & 0.909 \\
$Z$ value & -1.368 \\
$p$ value & .171 \\
Gini coefficient & .123 \\
Coefficient of variation & .236 \\
\hline
\end{tabular}

the 88 Ohio counties. The closer the value of the Gini coefficient is to 0 , the more even the distribution. In this case, the Gini for Medicaid expenditures is .123, also indicating a fairly even distribution of Medicaid expenditures across all counties.

Although the CV and Gini can be used to measure dispersion across spatial units, they are global measures that are independent of the spatial patterns in the data. To capture whether areas of above-average and below-average Medicaid spending per capita cluster together, we can make use of some spatial statistics. Indices such as the Moran's $I^{8}$ or Geary's $C^{9}$ have been developed to measure spatial correlation (Cliff \& Ord, 1981). Statistical inference for both can be made based on the standard normal data distribution. The Moran's $I$ value for Medicaid expenditures across Ohio counties of .103, with a corresponding $Z$ value of 1.759 and $p$ value of .079 , provides weak evidence of systematic patterns in the distribution of the per capita Medicaid expenditures across the counties. The Geary's $C$ value of 0.909 $(Z$ value $=-1.368, p$ value $=.171)$ provides further evidence that whatever variation exists in Medicaid expenditures is randomly distributed across the state.

\section{Indices as Indicators of Preference}

In economics, reservation prices not only represent the value society places on different commodities, but they often implicitly serve as weights depicting societal values. However, prices are only one indicator of society's preferences. In fact, we can develop a number of different weighting schemes to more accurately capture the different perspectives policy makers might use to study consequences of policy changes.

Changes in Medicaid funding have wide-ranging consequences that can be measured in terms of both health outcomes and financial implications. These consequences can be measured in various ways. For instance, we can study the implications for Medicaid recipients, for the health care industry, for local governments, or for the effect on the incidence of poverty. Because the affected populations are not randomly distributed, examination of the implications of policy changes on any of the populations has spatial implications in terms of where these consequences will fall. Next, we describe an easy way to incorporate these considerations into an exploration of the spatial implications of policy changes. 


\section{Dependence Indices for Local Economies}

One sensible approach to providing valuable insight into spatial variation is to measure how local conditions vary from a norm. A common, simple descriptive tool from regional economics, the location quotient, is useful for measuring how a particular measure in one location compares to an overall average. For example, in the economic development literature, location quotients are often used as indicators of how specialized a particular region is in any particular industry (Miller, Gibson, \& Wright, 1991).

By expressing a ratio of two proportions, a location quotient provides a relative measure of how specialized or dependent the local geographic unit (e.g., county) is in a particular measure relative to the more global unit (e.g., state). For example, a location quotient measuring the dependence of the local economy on expenditures in a particular Medicaid service category, such as nursing facilities, is expressed in Equation 1. The index measures the ratio of the proportion of the total expenditures in a county on services for that category to the proportion of the total expenditures in the state on those services. More formally, the ratio of the two proportions of expenditures on Medicaid service $s$ can be written as follows:

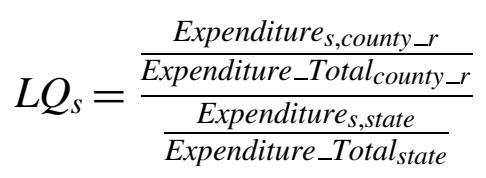

where Expenditure $e_{s, \text { county } r}$ and Expenditure ${ }_{s, \text { state }}$ represent expenditures on Medicaid service $s$ in county $r$ and for the whole state. Expenditure_Total county $r_{r}$ and Expenditure_Total state $_{\text {e }}$ measure total Medicaid expenditures in county $r$ and for the whole state. Therefore, if $\mathrm{LQ}_{\mathrm{s}}=1$, the county is at the state average, meaning that the proportion of expenditures in the county in that sector is the same as at the state level; if $\mathrm{LQ}_{\mathrm{s}}>1$, the county is more dependent than the state average, which means that the county has a higher dependence on expenditures in that sector than the state as a whole; and if $\mathrm{LQ}_{\mathrm{s}}<1$, the county is less dependent than the state average.

Using the location quotients, we can construct county-level dependence indices (DIs) to help capture the variation in economic conditions across the state in terms of local dependence (Greenbaum \& Desai, 2005). To incorporate complementary measures of a particular characteristic, each DI is computed as the geometric mean of three individual location quotients. Therefore, DIs are interpreted the same way as location quotients, with values greater than 1 indicating more dependence than the overall state average.

To help take into account the ability of recipients or health care providers to absorb changes in Medicaid expenditures, we construct two DIs that measure the reliance of counties on public assistance and the health services sector:

$$
\begin{aligned}
& P I=\left(L Q_{\text {Transferpayments }} \times L Q_{\text {Poverty }} \times L Q_{\text {Medicaid }}\right)^{1 / 3} \\
& H I=\left(L Q_{\text {Establishment }} \times L Q_{\text {Employment }} \times L Q_{\text {Payroll }}\right)^{1 / 3}
\end{aligned}
$$

The Poverty Index (PI) is based upon three measures of poverty, each of which is represented as location quotient: (a) federal transfer payments, (b) the number of households 
Figure 2

Expenditures per Recipient Weighted by Poverty Index, State Fiscal Year 2003

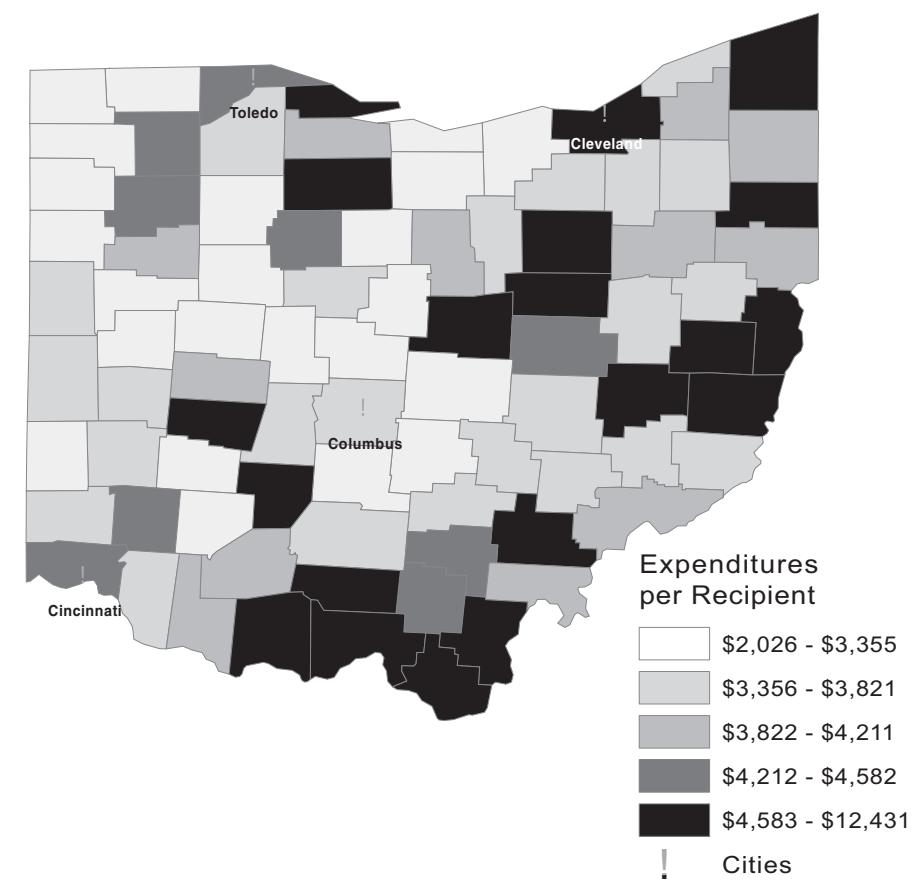

Source: Constructed by the authors.

with incomes below $100 \%$ of the federal poverty level, and (c) Medicaid expenditures per household. The Health Index (HI) is based upon three location quotients measuring how reliant the local economy is on the health services sector: (a) the number of establishments in the healthcare sector, ${ }^{10}(\mathrm{~b})$ employment in these establishments, and (c) associated payroll in these establishments. The values for both of these indices range from approximately 0.5 to 2 , providing another indication of the diversity across the state in terms of levels of poverty and extent of the role that health care services play in the local economy. A value of 1 indicates that the county is just as dependent as the rest of the state.

Indices such as these can be used as weights that serve to operationalize different perspectives of policy impacts depending upon whether we focus, for example, on the consequences for the health care industry or for vulnerable populations. By incorporating these weights into the GIS, the policy debate can be better informed by providing visual representations of how particular policy values can affect perceptions of the policy choices and their consequences.

To illustrate how the indices can be used to help better inform policy decisions, the PI and $\mathrm{HI}$ are used to weight the Medicaid expenditures per recipient in each county. The weighted data from Figure 1 are displayed in Figure 2 and Figure 3.

Weighting the expenditures in this manner arguably provides a more relevant indication of the potential effects of expenditure changes on various counties. The two maps show which 
Figure 3

Expenditures per Recipient Weighted by Health Index, State Fiscal Year 2003

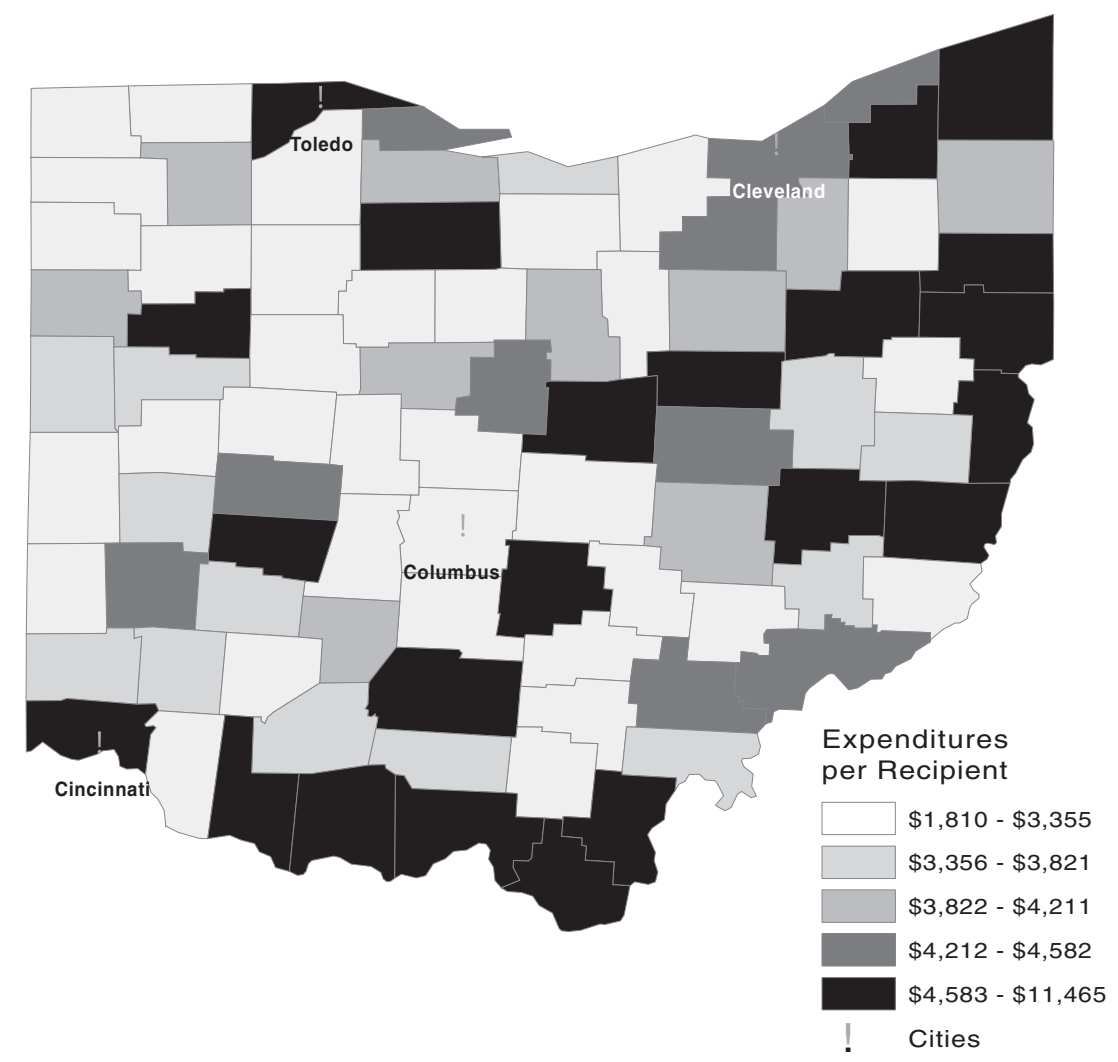

Source: Constructed by the authors.

counties would likely be the most vulnerable to the burden of cost-management measures. They differ from each other, and they are both different from the unweighted Figure 1. The per capita expenditures weighted by the PI (see Figure 2) indicate that the highest expenditures per recipient are located in the eastern and southern Appalachian counties. Unlike in Figure 1, the wealthier western counties no longer contain any of the highest expenditures per recipient. In Table 3, the Moran's I (.158) confirms the visual evidence that the weighted recipient expenditures are clustered in space $(Z$ value $=2.589$ and $p$ value $=.010)$. The Geary's $C$ statistic (0.830) also indicates spatial clustering $(Z$ value $=-2.551$ and $p$ value $=.011)$. The distribution of expenditures per recipient weighted by the Health Index (see Figure 3 ) is more similar to Figure 2 than Figure 1, but there are some important differences, such as even lower HI-weighted expenditures per recipient (lightest shading) in the central counties. However, the Moran's $I(.037, Z$ value $=0.741$ and $p$ value $=.459)$ and Geary's $C(0.945$, $Z$ value $=-0.822$ and $p$ value $=.411)$ statistics indicate that this distribution is not statistically significantly spatially autocorrelated when the expenditures are weighted by the HI. 
Table 3

Policy Criteria and Spatial Statistics

\begin{tabular}{|c|c|c|c|c|c|c|}
\hline \multirow[b]{2}{*}{$\begin{array}{l}\text { Policy Criteria } \\
\text { Operationalization }\end{array}$} & \multirow{2}{*}{ 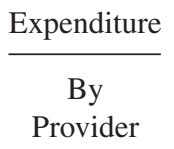 } & \multicolumn{2}{|c|}{ Local Economy } & \multicolumn{3}{|c|}{ Service Category } \\
\hline & & $\begin{array}{l}\text { Poverty } \\
\text { Index }\end{array}$ & $\begin{array}{l}\text { Health } \\
\text { Index }\end{array}$ & $\begin{array}{l}\text { Prescription } \\
\text { Drug }\end{array}$ & $\begin{array}{l}\text { Nursing } \\
\text { Facility }\end{array}$ & Dental \\
\hline Map & Figure 4 & Figure 2 & Figure 3 & Figure 5 & Figure 6 & Figure 7 \\
\hline Areas "disadvantaged" & Urban & Southeast & $\begin{array}{l}\text { Northeast/ } \\
\text { South }\end{array}$ & $\begin{array}{c}\text { South/ } \\
\text { Southeastern }\end{array}$ & West & South \\
\hline \multicolumn{7}{|l|}{ Spatial statistics } \\
\hline \multicolumn{7}{|l|}{ Moran's I } \\
\hline$I$ & .101 & .158 & .037 & .020 & .029 & -.033 \\
\hline$Z$ value & 1.729 & 2.589 & 0.741 & 0.475 & 0.626 & -0.326 \\
\hline$p$ value & .084 & .010 & .459 & .635 & .531 & .745 \\
\hline \multicolumn{7}{|l|}{ Geary's $C$} \\
\hline$C$ & 0.893 & 0.830 & 0.945 & 0.968 & 0.968 & 0.964 \\
\hline$Z$ value & -1.608 & -2.551 & -0.822 & -0.475 & -0.466 & -0.530 \\
\hline$p$ value & .108 & .011 & .411 & .635 & .641 & .596 \\
\hline Gini coefficient & .199 & .199 & .179 & .177 & .217 & .176 \\
\hline Coefficient of variation & .354 & .379 & .381 & .412 & .312 & .812 \\
\hline
\end{tabular}

These weighted versions indicate how placing an emphasis on the health care industry or on regional poverty can lead to different interpretations of who would bear the burden of changes in Medicaid expenditures. They help clarify how using different weighting schemes based on policy makers' preferences would lead to different visualizations of the data and potentially different decisions.

The choice of weights and weighting schemes becomes important to the extent that policy analysis helps frame the policy discussion and identify the set of choices available to the decision makers. By choosing different criteria for selecting weights, the analysis focuses attention on different consequences. For instance, evaluation criteria focused on intergenerational consequences might yield weights that are very different from those that focus on the concentration of the health care industry or on regional poverty. Hence, the analyst's decision regarding what weights to depict and the secondary decisions by the policy makers, based on the analyst's weighted maps, will lead to different consequences. In this case, the analysis has focused on the health care industry and poverty. If the decision makers choose to focus on these weighted maps, then it is no surprise that the set of decision choices and their consequences will be different than those based on the unweighted expenditures in Figure 1.

Additional insight into the relative concentration or sparseness of expenditures in a given county can be gained through further analysis of the geographical distribution of the consequences of expenditure changes. Consider two different representations of Medicaid expenditures in Ohio. As before, we can view the county-level distribution of Medicaid expenditures in terms of where the recipients live (recipient expenditures), or alternatively, we can show the distribution in terms of where the services are provided (provider expenditures). 
Figure 4

Medicaid Provider Expenditures per Recipient, State Fiscal Year 2003

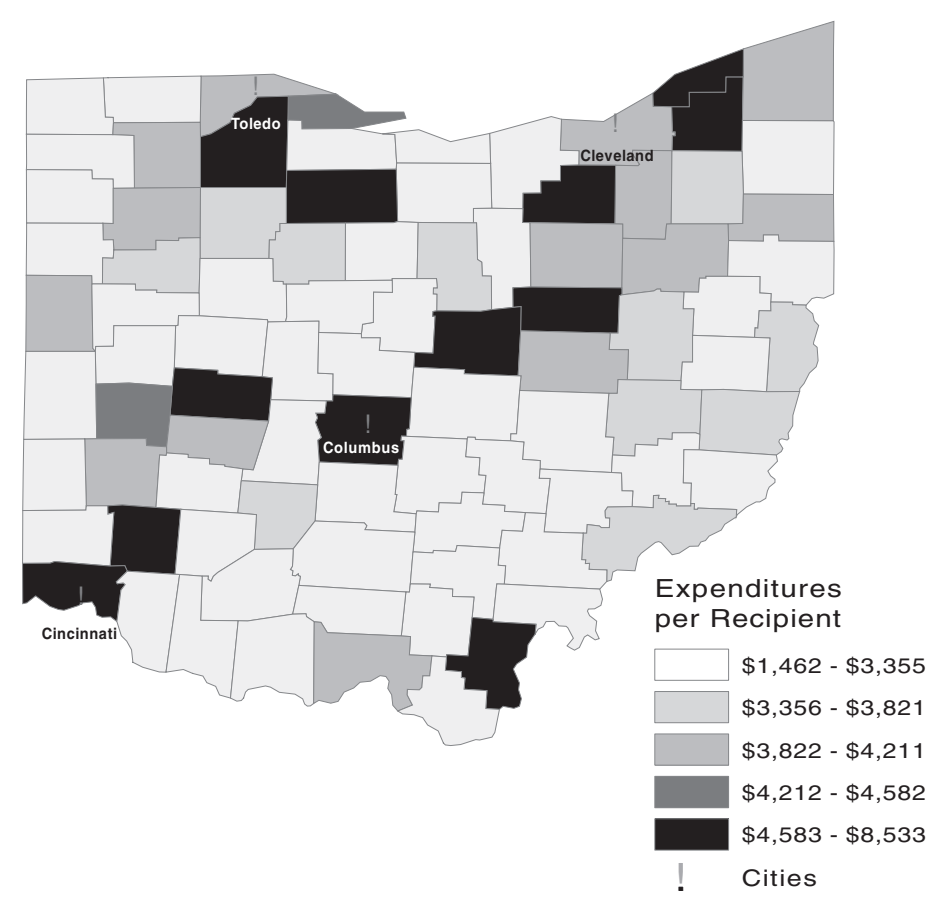

Source: Ohio Department of Job and Family Services 2003 county-level data on Medicaid recipients and expenditures.

A visual representation of the distribution of the expenditures across all providers in the different counties is provided in Figure 4. The difference between this map and Figure 1 helps further clarify the different aggregation procedures used. For both maps, we count the recipients in the county in which they reside. There is a difference, however, in the way in which the expenditures are computed.

The expenditures in Figure 1 are those expenditures (recipient expenditures) by the residents of the county without attention to where the monies were spent. In Figure 4, the expenditures (provider expenditures) are attributed to the county in which the service was provided. Hence, in general, the urban counties in the southwest (Cincinnati area), central (Columbus area), north-central (Toledo area) and northeast (Cleveland area) parts of the state, where many recipients receive their services, would have disproportionately high provider expenditures. There are some rural counties with relatively few Medicaid recipients but with high-cost services resulting in high provider expenditures. The difference between Figure 1 and Figure 4 is interesting in that these maps distinguish between counties in which recipients who receive a number of high-expenditure services reside versus counties which provide either a high volume of services or have high-expenditure service providers.

Compared to Figure 1, Figure 4 shows the larger variability in the per recipient expenditures from a county average low of $\$ 1,462$ to a high of $\$ 8,533$ around the overall average 
of $\$ 3,997$ in SFY2003. The Moran's $I$ for the distribution of provider expenditures is .101 $(Z$ value $=1.729$ and $p$ value $=.084)$. The Gini coefficient is .199 , which is slightly higher than that of Figure 1 (.123).

For a policy maker, Figures 1 and 4 represent the perspectives of two different interest groups. To evaluate the consequences of policy changes, counties with a number of service providers will focus on Figure 4, whereas counties with a large number of recipients will focus on Figure 1. There is nothing profound in this observation, other than that it illustrates the ease with which data visualization can be achieved to represent different perspectives of the same information.

\section{Expenditure DIs for Service Categories}

So far, we have demonstrated how the location quotient can be used for weighting the data by using it as an index to incorporate preferences or criteria to emphasize or de-emphasize deviations from some norm. Marrying that to a GIS allows us to visualize the data distributions and to compute statistics that can supplement the visual images and the impressions they create.

Policy changes in a program as large as Medicaid are rarely made across the board. Instead, changes are usually made in specific areas. For instance, changes in eligibility can expand or reduce coverage, or changes in payment schedules only affect those providers who offer the affected services. Again, an index based on the location quotient can be used to estimate the differential spatial effects of the policy changes.

We provide different pictures in the following three maps using another type of DI. These maps show how each county's dependence on a particular Medicaid service compares with that of the state in terms of provider expenditures. We first compute the ratio of expenditures in a particular service category as a proportion of the total Medicaid expenditures. We obtain that ratio for both the state and the county. Hence, we now know what proportion of each (e.g., expenditures on prescription drugs) is of the total Medicaid expenditures in the state and in each of the 88 counties.

Medicaid data indicate that expenditures in 2003 on prescription drugs were approximately $17 \%$ of all Medicaid expenditures in the state. We compute the same ratio for each of the counties. In some counties, the percentage will be higher than $17 \%$ and in others it will be lower. Therefore, when we take the ratio of the county percentage to the state percentage, we will get indices that range around 1 . A value close to 1 indicates that the proportion of provider expenditures on prescriptions in that county is close to $17 \%$, the state level.

Figure 5 indicates that this ratio for provider expenditures on prescription drugs ranges from a low of less than a half (0.435) to a high of almost 3 (2.931). Hence, in the lowest county, prescription drugs account for a little more than $7 \%$ of the total Medicaid provider expenditures, whereas in the highest county the percentage is almost 50\%. Again, the southern and southeastern counties have the greatest dependence on prescription drug expenditures. However, unlike the majority of the previous maps, the northeast counties are not among the most dependent on pharmaceutical spending. Consequently, any policy changes in prescription drug coverage or expenditure growth will affect the darker shaded counties much more than it will affect the lighter shaded counties. 
Figure 5

Dependence Index: Prescription Drugs

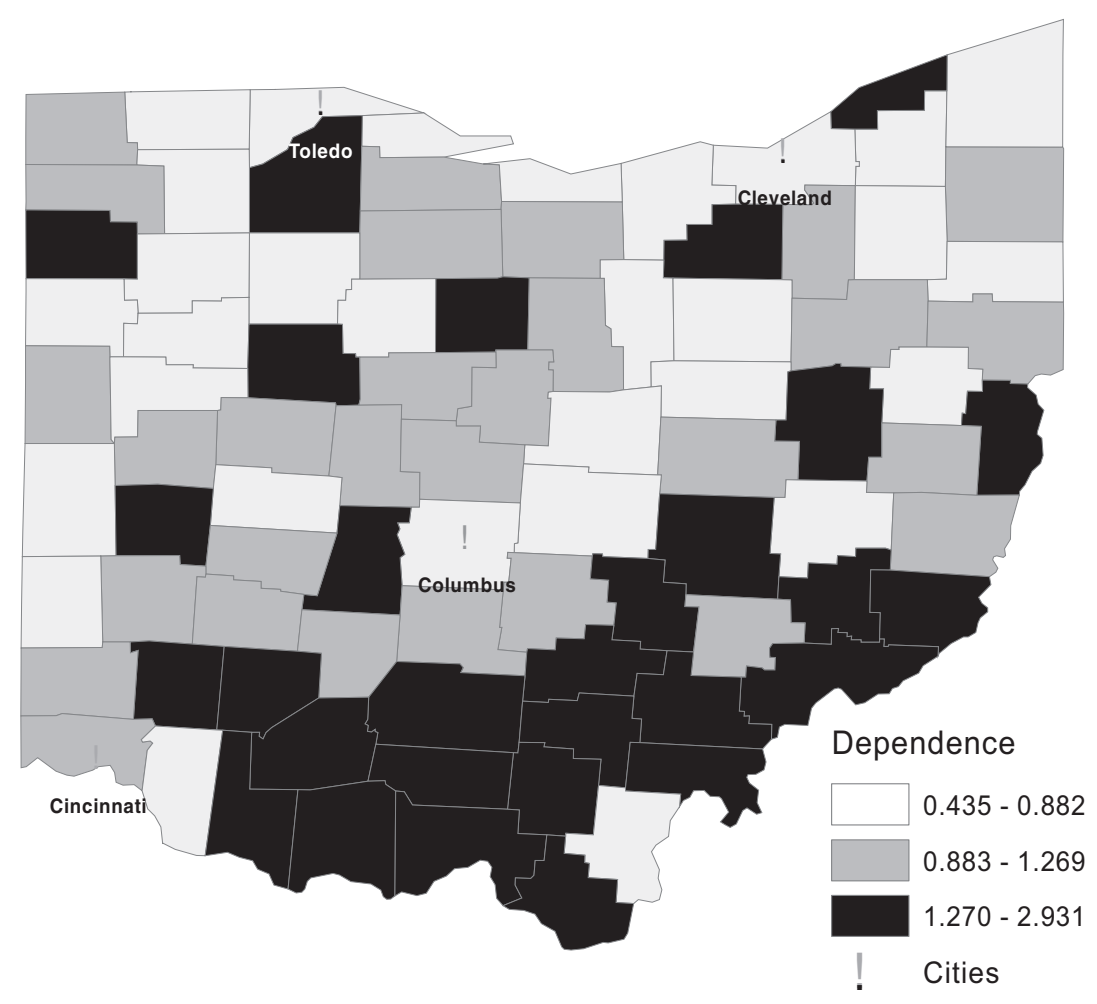

Source: Constructed by the authors.

Although the southern and southeastern counties are most dependent on Medicaid expenditures, Figure 6 suggests that the nursing facilities make up a large portion of Medicaid dollars spent in the western counties. The nursing facilities DI values range from 0.472 in the lowest county to 2.279 in the highest county. Thus, expenditures range from as low as $15 \%$ in the lowest county to almost $70 \%$ of the total Medicaid expenditures in the highest county, and the mean proportion of state expenditures on nursing facilities is approximately $30 \%$.

Dental expenditures account for less than $1 \%$ of total Medicaid expenditures in the state. Hence, from an overall economic effect perspective, reductions in dental expenditures do not make much of an impact on the Medicaid budget, but they do make a tremendous impact on individuals. In that larger budgetary context, the fact that two counties (see Figure 7) have no Medicaid-funded dental providers (hatched shading) or that the highest county dental provider expenditures are almost 6 times the state level is of little consequence.

However, the dark-shaded cluster of counties in the southern part of the center of the state is most severely affected in this instance by the elimination of funding for dental care 
Figure 6

Dependence Index: Nursing Facilities

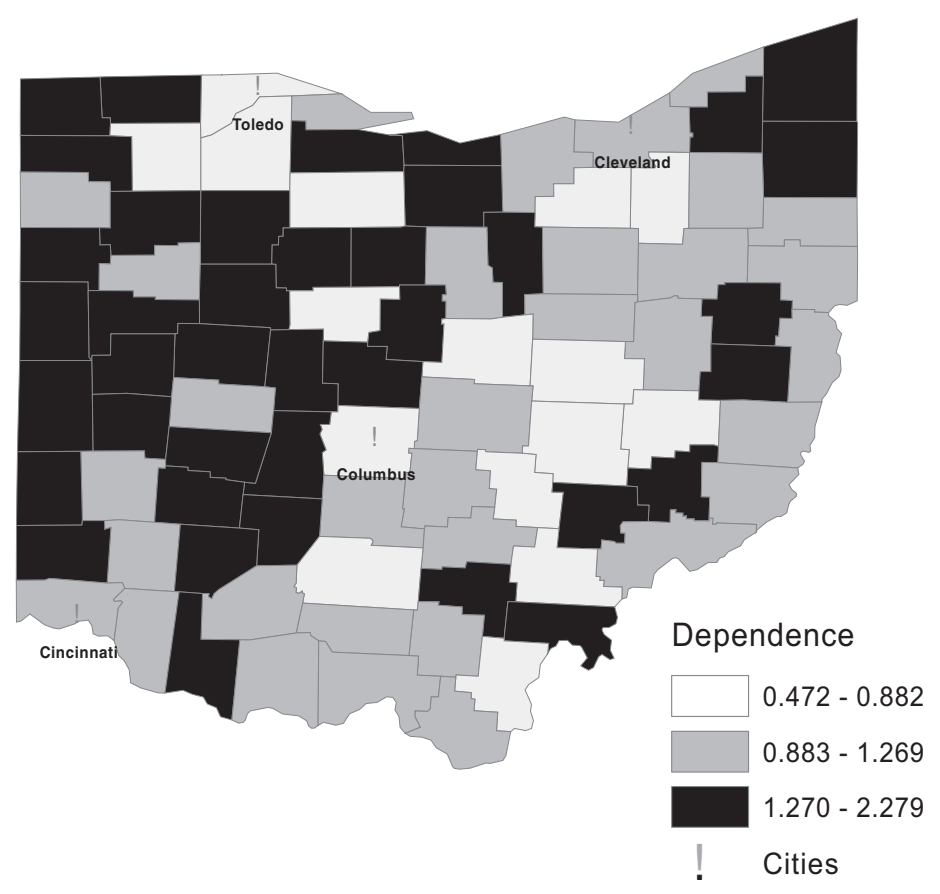

Source: Constructed by the authors.

for adults. Lack of access to dental care is also associated with long-term health problems that develop later in life (Gregory, Gibson, \& Robinson, 2005; Zabos et al., 2002). Hence, seemingly minor budgetary changes today can have serious implications for the future.

The Gini coefficient shows that the overall distribution of Medicaid dental service provision (.395) is less equal than the distribution prescription drugs (.217) and nursing facilities (.176). Nevertheless, the Moran's $I$ and the Geary's $C$ show that the spatial clustering of Figures 5, 6, and 7 are not meaningful. The Moran's $I$ for the distribution of prescription drugs (Figure 5) is $.020(Z$ value $=0.475$ and $p$ value $=.635)$. The Geary's $C$ is 0.968 $(Z$ value $=-0.475$ and $p$ value $=.635)$. The Moran's $I$ for the distribution of nursing facility (Figure 6) is $.029(Z$ value $=0.626$ and $p$ value $=.531)$. The Geary's $C$ is $0.968(Z$ value $=$ -0.466 and $p$ value $=.641$ ). The Moran's $I$ for the distribution of dental services (Figure 7) is $-.033(Z$ value $=-0.326$ and $p$ value $=.745)$. The Geary's $C$ is 0.964 ( $Z$ value $=-0.530$ and $p$ value $=.596$ ).

The level of sophistication of the data displayed in Figure 1 is no different from that in subsequent maps. However, the last three maps show ratios of expenditures data, disaggregated by type of service, that highlight the variation in per recipient expenditures in comparison to the state-level average. These maps help identify the effects of changes in specific 
Figure 7

Dependence Index: Dental Service

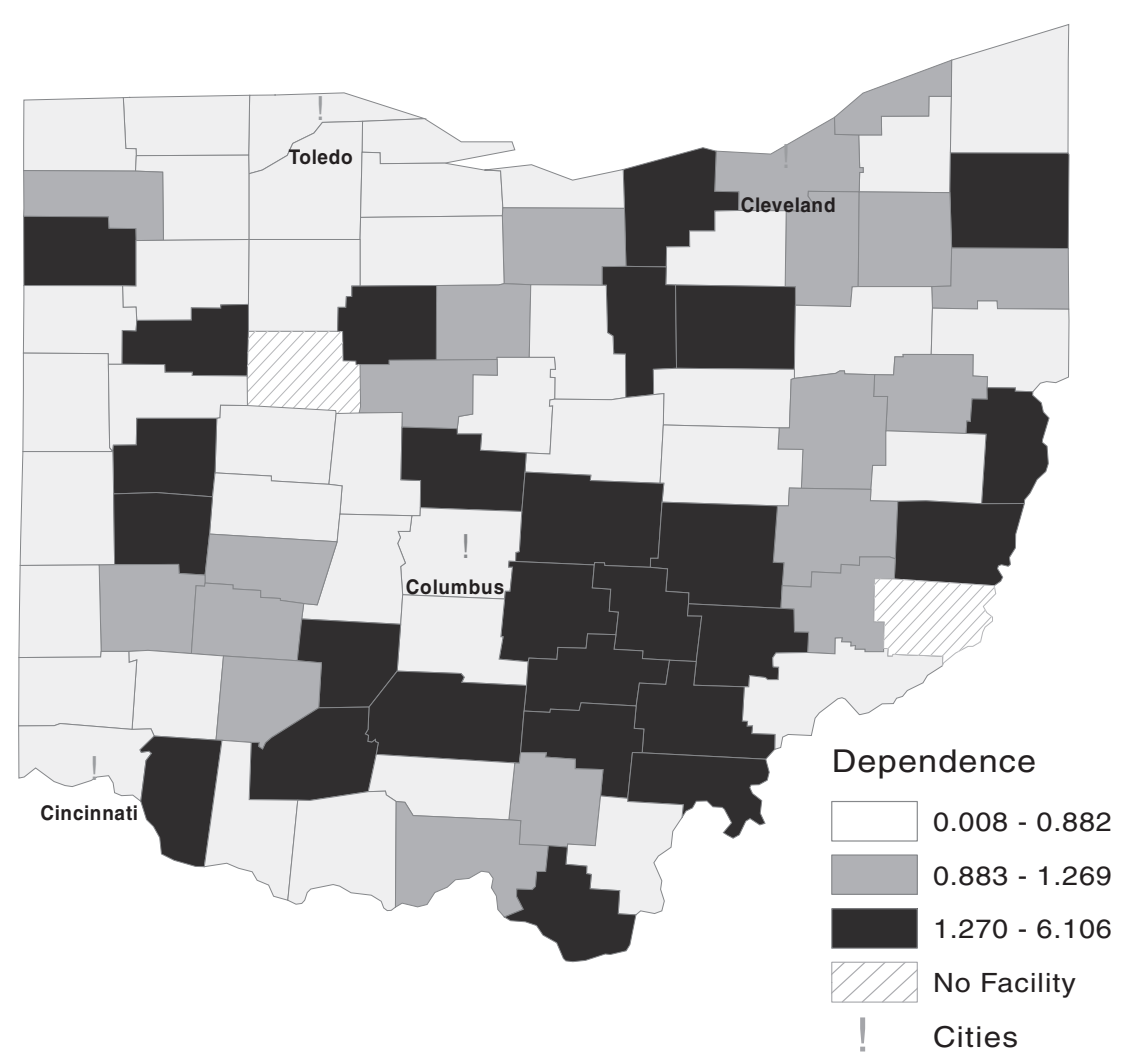

Source: Constructed by the authors.

programs and identify where these changes would have the greatest consequences. By focusing on types of service, it is possible to determine how changes in any one or a combination of services would affect the individual counties. In particular, such an analysis would shed light on whether the consequences of these changes are concentrated in given areas or are evenly distributed across the counties.

A note of caution must accompany these maps. Although these maps provide specific information on expenditures by service category, they also hide other policy-relevant information. The expenditures represented in each map vary considerably across the service types. In other words, the amounts of money each of these three maps represents are vastly different. Consider, for instance, the expenditures on prescription drugs and expenditures on dental services. The prescription drugs represent a substantially larger percentage of the Medicaid budget than do dental expenditures. Furthermore, the short-term and long-term consequence, say, of reduced expenditures on prescription drugs would be very different from those due to reduced dental expenditures. 


\section{Summary}

Traditional GIS analyses focus on spatial relationships in the data. Spatial statistics (Anselin, 1988) and weighting matrices (Martin, 1996) usually focus on physical distances or spatial proximity. Spatial statistics such as Moran's $I$ or Geary's $C$ provide tests of whether the observed spatial patterns are random (Cliff \& Ord, 1981).

The ratios and weights we have proposed here are not intrinsically spatial indicators. We have computed and displayed different DIs. The first pair of indices use data on the health care industry and poverty to illustrate that focusing on one or the other could lead to different policy recommendations. Those indices are based upon the recipient expenditures, expenditures by Medicaid recipients living in a county. The second set of indices makes use of provider expenditures, expenditures by providers offering services in that county. From an economic consequence perspective, counties in which there are larger provider expenditures relative to recipient expenditures are potentially attracting more Medicaid dollars in relative terms. In the event of reduced expenditures, they have "more to lose" compared to those counties in which there are fewer expenditures contributing to the economic vitality of the county. Maps such as these can help policy makers at both the state level and in the affected counties anticipate and plan to cope with the implications of the policy changes.

Compared to the expenditure ratios, the health and poverty indices are more explicit indicators of preference. Depending upon how they are constructed (i.e., depending on what variables are used to construct these indices), decision makers can explore their own notions of inequity and its spatial distribution within the state. Once they decide which type of perceived inequity they wish to ameliorate, they can design policies to influence the outcomes.

To summarize, we have followed a three-step analytical process.

1. We have made the traditional use of GIS to illustrate spatial variations in policy relevant information on a map.

2. We used location quotients to develop and illustrate the use of weights.

3. We used spatial statistics to supplement the visual impressions created by the maps to provide robust analyses of the consequences of policy changes.

\section{Discussion}

The intent of this article has not been to demonstrate that there is a single best weighting scheme or data display. Rather, we suggest that the policy analyst should offer multiple options based on analytic tools such as those described above. The analyst should educate decision makers regarding the assumptions that underlie each analysis and should understand that the statistical analysis is only one of the many factors that ultimately inform a final decision.

The analyst also maintains an obligation to use these tools in an ethical manner. Although we demonstrated that a GIS, when used properly, can be a powerful data visualization tool that is invaluable in informing public policy choices, we offer caution that it is not always obvious what constitutes proper use. The weighting schemes we have proposed produce different manifestations or distortions of the maps. There is a fine line between such distortions that depict 
different emphases and outright misrepresentations of the data. Indeed, Tufte (1983) demonstrates how easy it is to misrepresent the visualization of data in subtle ways. Monmonier (1996, p. 25) further suggests that "a good map tells a multitude of white lies," because even when simply representing physical features, a mapmaker must make multiple and complex decisions regarding which features to highlight and which to suppress. The mapmaker's problem is compounded when the data visualization software has the capability to merge multiple data sets, manipulate the data, and display the information in attractive formats.

GIS, in common with other decision support tools, is used to assist decision making under uncertainty. Unfortunately, we do not have an agreed upon standard for displaying information uncertainty in maps (MacEachren et al., 2005). This lack of consensus may be because in part, uncertainty remains an ambiguous concept. In this regard, we take the hopeful view that this shortcoming offers a wide range of opportunities for research, but it also serves as a caution for users of GIS output that it is important to be able to assess its reliability and accuracy.

Finally, as with any analysis, there is an asymmetry in the information available to producers and consumers of the analysis. GIS allow for a wide array of data manipulations and computations that are displayed on seemingly similar maps. In the absence of proper knowledge of how the data were manipulated, the consumer is, almost always, at a disadvantage relative to the producer.

However, the consumer has a complementary set of responsibilities to ensure that the information displays are credible and true to the underlying assumptions. At a minimum, the analyst must provide information regarding the source of the data, the assumptions underlying the data generation and analysis, and must be explicit about the weighting and other manipulations of the data and their representations. Similarly, it is incumbent upon the user of such information to demand multiple representations or sensitivity analyses to gauge the robustness of the results across different sets of assumptions.

Data, and particularly data presented on maps, can be very persuasive. Thus, the conscientious analyst will use these powerful analytic tools to provide the consumers of the analysis policy options with the appropriate cautions regarding assumptions that were made.

\section{Notes}

1. Available from http://www.census.gov/geo/www/tiger/index.html

2. Available from http://www.epa.gov:80/enviro/html/ef_overview.html

3. Available from http://www.bea.doc.gov/bea/glance.htm

4. Although 2003 data may seem dated, they offer a complete and best set of information for the illustrative purpose of this article.

5. In all maps, darkest shading shows the highest value. The classification of values is based on quintiles. For the purpose of comparison to Figure 1, we applied the same classification ranges in Figure 2, Figure 3, and Figure 4. The same logic for classification with three classes was applied for Figure 5, Figure 6, and Figure 7.

6. The coefficient of variation $(\mathrm{CV})$ shows the degree to which a set of data points vary. Typically, the CV is presented as a percentage: $\mathrm{CV}=($ standard deviation / mean $) \times 100$. Thus, the higher the $\mathrm{CV}$, the greater the variability there is in the data.

7. According to Morgan (1962), it is also the best measure of inequality.

8. Moran's $I=\frac{n \sum_{i} \sum_{j} w_{i j}\left(x_{i}-\bar{x}\right)\left(x_{j}-\bar{x}\right)}{\left.\left(\sum_{i} \sum_{j} w_{i j}\right) \sum_{i}\left(x_{i}-\bar{x}\right)^{2}\right)}$, where $n$ is the number of observations, $x$ (with mean $\bar{x}$ ) is the variable of interest in location $i$ and location $j$, and $\mathrm{w}_{i j}$ are elements of a spatial weighting matrix (a binary contiguity matrix in this case). 
9. Geary's $C=\frac{\left[(n-1)\left[\sum_{i} \sum_{j} w_{i j}\left(x_{i}-x_{j}\right)^{2}\right]\right]}{2\left(\sum_{i} \sum_{j} w_{i j}\left(x_{i}-\bar{x}\right)^{2}\right)}$, where $C$ ranges between 0 and 2, with 1 representing no spatial autocorrelation.

10. The "health care and social assistance" sector (North American Industry Classification System 62) includes all public and private health care establishments as well as other care facilities.

\section{References}

Anselin, L. (1988). Spatial econometrics: Methods and models. Dordrecht, Netherlands: Kluwer.

Brown, M. M., \& Brudney, J. L. (1998). A smarter better, faster and cheaper government: Contracting and geographic information systems. Public Administration Review, 58(4), 335-346.

Bureau of Economic Analysis. (2001). Regional Economic Information System (REIS): CA05.1. Washington, DC: Author.

Cliff, A. D., \& Ord, J. K. (1981). Spatial processes: Models and applications. London: Pion.

Desai, A., Kim, Y., \& Greenbaum, R. (2005, December). Estimating local effects of medicaid expenditure changes. Retrieved from http://www.healthpolicyohio.org/pdf/MedicaidExpendReport.pdf.

Division of Research. (2002, January). Economic impact of Medicaid on South Carolina. Columbia: University of South Carolina, Moore School of Business.

Foresman, T. W. (Ed.). (1998). The history of geographic information systems: Perspectives from the pioneers. Upper Saddle River, NJ: Prentice Hall.

Greenbaum, R. T., \& Desai, A. (2005). Viewing spatial consequences of budgetary policy changes. Public Budgeting \& Finance, 25(2), 43-60.

Gregory, J., Gibson, B., \& Robinson, P. G. (2005). Variation and change in the meaning of oral health related quality of life: A 'grounded' systems approach. Social Science \& Medicine, 60(8), 1859-1868.

Haque, A. (2001). GIS, public service, and the issue of democratic governance. Public Administration Review, 61, 259-265.

The Health Policy Institute of Ohio. (2007). Ohio Medicaid basics 2007, Columbus: Author.

Hissong, F., \& Couret, C. (1999). Will locals lead the way to a national GIS? American City and County, 114(9), 22-28.

Kilpatrick, K. E., Olinick, J., Luger, M. I., \& Koo, J. (2002, April). The economic impact of proposed reductions in Medicaid spending in North Carolina. Chapel Hill: University of North Carolina.

MacEachren, A. M., Robinson, A., Hopper, S., Gardner, S., Murray, R., Gahegan, M., et al. (2005). Visualizing geospatial information uncertainty: What we know and what we need to know. Cartography and Geographic Information Science, 32(3), 139-160.

Martin, D. (1996). Geographic information systems: Socioeconomic applications. London: Routledge.

Marton, J., \& Wildasin, D. E. (2007). Medicaid expenditures and state budgets: Past, present, and future. National Tax Journal, 60(2), 279-304.

Masser, I. (1998). Governments and geographic information. Bristol, PA: Taylor \& Francis.

McGarry, K. (2002). Public policy and the U.S. health insurance market: Direct and indirect provision of insurance. National Tax Journal, 55(4), 789-827.

Miller, M. M., Lay, J. G., \& Wright, N. G. (1991). Location quotient basic tool for economic development analysis. Economic Development Review, 9(2), 65-68.

Monmonier, M. (1996). How to lie with maps (2nd ed.). Chicago: University of Chicago Press.

Morgan, J. (1962). The anatomy of income distribution. The Review of Economics and Statistics, 44(3), 270-283.

National Academy of Public Administration. (1998). Geographic information for the 21 $1^{\text {st }}$ century: A strategy for the nation. Washington DC: Author.

National Governors Association. (2003). The Fiscal Survey of States: June 2003. Washington, DC: Author and the National Association of State Budget Officers.

Office of Strategic Research. (2002). Ohio county profiles. Columbus: Ohio Department of Development.

O'Looney, J. (2000). Beyond maps: GIS and decision making in local government. Redlands, CA: ESRI Press. 
Seninger, S. (2003). Economic impact of Medicaid on Montana and on the Billings, Butte, and Miles City healthcare market areas. Missoula: University of Montana-Missoula Campus.

Smith, V., Ellis, E., Gifford, K., Ramesh, R., \& Wachino, V. (2002). Medicaid spending growth: Results from a 2002 survey (Publication 4064). Washington, DC: Kaiser Commission on Medicaid and the Uninsured.

Tufte, E. R. (1983). The visual display of quantitative information. Cheshire, CT: Graphic Press.

U.S. Census Bureau. (2001). Census of population and housing (2000). Washington, DC: U.S. Department of Commerce.

U.S. Census Bureau. (2002). County business patterns for Ohio (2000). Washington, DC: U.S. Department of Commerce.

Ventura, S. J. (1995). The use of geographic information systems in local government. Public Administration Review, 55(5), 461-467.

Wildavsky, A. B. (1987). Speaking truth to power: The art and craft of policy analysis. New Brunswick, NJ: Transaction Books.

Worrall, L., \& Bond, D. (1997). Geographical information systems, spatial analysis and public policy: The British experience. International Statistical Review, 65, 365-379.

Zabos, G. P., Northridge, M. E., Ro, M. J., Trinh, C., Vaughan, R., Howard, J. M., et al. (2002). Lack of oral health care for adults in Harlem: A hidden crisis. The American Journal of Public Health, 92(1), 49-52.

Anand Desai is a professor in the John Glenn School of Public Affairs at The Ohio State University. His research interests include the use of mathematical modeling, data display, analysis, and synthesis to inform decision making in the public sector. His research has been published in various journals including Communications of the Association of Computing Machinery, Decision Sciences, Environment and Planning, and Public Budgeting \& Finance.

Robert T. Greenbaum is an associate professor in the John Glenn School of Public Affairs and associate director of the Center for Urban and Regional Analysis at The Ohio State University. His research focuses on urban and regional economic development, with a focus on examining business tax incentives, crime and terrorism, and spatial analysis. He has most recently published in Urban Studies, Regional Science and Urban Economics, and the Journal of Quantitative Criminology.

Yushim Kim is an assistant professor in the School of Public Affairs at Arizona State University. Her research interests are public policy analysis and policy informatics. She has framed conceptual questions in these areas in the context of public service delivery and public health/welfare policy. Her research has appeared in Social Science Computer Review and Interdisciplinary Description of Complex Systems. 